\title{
Temperaments and characters: incompatible or complementary components for criterion $B$ of the alternative model in predicting DSM-5 section II personality disorders?
}

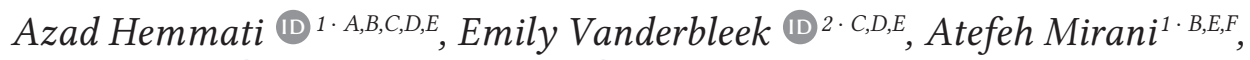 \\ Lee A. Clark (DD ${ }^{2 \cdot D, E}$, Farzin Rezaei (D) ${ }^{3 \cdot A, E}$ \\ 1: University of Kurdistan, Sanandaj, Iran \\ 2: University of Notre Dame, Notre Dame, IN, United States \\ 3: Kurdistan University of Medical Sciences, Sanandaj, Iran
}

BACKGROUND

Many studies have found clear correspondence among the domains of the five-factor model of personality (FFM) and the alternative model of personality disorders (AMPD) in DSM-5-III, which is assessed with the Personality Inventory for DSM-5 (PID-5). However, very few studies have compared the PID-5 with the other well-known established dimensional models of personality such as Cloninger's model. The present study examined whether the Temperament and Character Inventory (TCl-125) dimensions, PID-5 dimensions, or a combination would represent PD-scale scores more accurately.

\section{PARTICIPANTS AND PROCEDURE}

In this regard, 437 college students completed the Persian version of the PID-5, TCI-125 and SCID-II Screening Questionnaire.

\section{RESULTS}

The results indicated that cooperativeness (low), self-directedness (low), and self-transcendence (high) characters of the TCl-125 and the psychoticism (high) domain of the PID-5 are the most consistent predictors of all PD-scale scores.

CONCLUSIONS

Overall, the findings showed that an integrative model, combining dimensions of the TCl-125 and PID-5, represented the features of PD-scale scores most effectively.

\section{KEY WORDS}

temperament and character inventory; alternative model for personality disorders; PID-5

CORResPonding Author - Azad Hemmati, Ph.D., Department of Psychology, University of Kurdistan, Pasdaran Str., 66177-15175 Sanandaj, Iran, e-mail: A.hemmati@uok.ac.ir

AUthors' CONTRIBUtion - A: Study design - B: Data collection - C: Statistical analysis - D: Data interpretation .

E: Manuscript preparation · F: Literature search · G: Funds collection

to CITE this ARTICLE - Hemmati, A., Vanderbleek, E., Mirani, A., Clark, L. A., \& Rezaei, F. (2021). Temperaments and characters: incompatible or complementary components for criterion B of the alternative model in predicting

DSM-5 section II personality disorders? Current Issues in Personality Psychology, 9(1), 1-13.

RECEIVED 07.07.2020 • REVIEWED 24.10.2020 • ACCEPTED 22.01.2021 • PUBLISHED 01.03.2021 


\section{BACKGROUND}

Due to the numerous and well-documented problems with the current diagnostic system of personality disorders (PDs), such as high rates of comorbidity and within-diagnosis heterogeneity, many researchers have determined that a categorical system of PDs is scientifically untenable and posit that personality instead should be measured dimensionally (Clark, 2005, 2007; Cloninger, 2000; Kendler, 2009; Krueger \& Markon, 2006; Trull \& Durrett, 2005; Widiger \& Simonsen, 2005). In particular, some meta-analytic review studies show that the five-factor model of personality (FFM; Widiger et al., 2002) provides a suitable framework for classifying PDs (Miller et al., 2004; Samuel \& Widiger, 2008; Saulsman \& Page, 2004). However, the FFM was designed to measure normal-range personality traits rather than personality pathology and thus may fail to capture the extreme ends of personality (e.g., Krueger et al., 2012). Subsequently, an alternative model that adopts a hierarchical dimensional approach to conceptualizing PD was proposed in Section III, Emerging Measures and Models, of the Diagnostic and Statistical Manual of Mental Disorders (DSM-5; American Psychiatric Association, 2013). The alternative model includes two main criteria: criterion A, personality-functioning impairment, and criterion $\mathrm{B}$, personality-trait pathology. Criterion $\mathrm{B}$ is based on a hierarchical trait model comprising five domain-level traits that were intended to represent maladaptive variants of the FFM traits - negative affectivity (vs. emotional stability), detachment (vs. extraversion), disinhibition (vs. conscientiousness), antagonism (vs. agreeableness), and psychoticism that in turn comprise 25 lower-order specific trait facets. To assess these traits, the Personality Inventory for DSM-5 was proposed (Krueger et al., 2012).

Researchers (see De Caluwé et al., 2019) have examined the associations among FFM and PID-5 traits to compare the structures of normal and pathological personality, respectively, and have found clear correspondence among the domains of negative affectivity and neuroticism, disinhibition and conscientiousness, and antagonism and agreeableness (Watson et al., 2013). More research is needed to compare the DSM-5-III model with established and widely used models of personality, including other well-known dimensional measures of personality traits such as Clark's Schedule for Adaptive and Nonadaptive Personality (SNAP-2; Clark et al., 2014) and Cloninger's Temperament and Character Inventory (TCI-125; Cloninger, 1994). Some studies have compared the PID-5 and the SNAP-2 (Clark et al., 2015; Jopp \& South, 2014; Miller et al., 2014). However, there is only one study (García et al., 2020) which compared the prediction of PID-5 scores from three personality trait models (FFM, Zuckerman \& Cloninger).
Cloninger's biopsychosocial model (Cloninger et al., 1993) differs significantly from the alternative model in DSM-5-III. The alternative model was derived from a careful analysis of the personality assessment literature and based partly on the FFM's hierarchical trait model; in contrast, Cloninger's model was developed by considering the underlying biological and social determinants of individual differences. Cloninger identified four temperaments or automatic emotional responses that are stable over time (novelty seeking, harm avoidance, reward dependence, and persistence), and three factors describing the character, or self-concepts and differences in goals and values (self-directedness, cooperativeness, and self-transcendence), which make up personality. Cloninger's model has been shown to relate to PDs; specifically, one study found that self-directness and cooperativeness characters were lower for patients diagnosed with PD and were inversely correlated with the number of PD criteria (Cloninger et al., 1993). Similarly, self-directedness and cooperativeness are lower in samples with high rates of personality pathology (e.g., forensic samples) compared to community samples (e.g., de la Rie et al., 1998; Svrakic et al., 1993).

Cloninger and Svrakic (in Sadock et al., 2017) proposed that the temperament and character dimensions clarify the bases of PD more effectively than models derived through factor analysis, such as the FFM or the DSM-5-III model, and criticized such models for establishing arbitrary cutoff points for continuous traits without specifying why certain traits are considered "disordered." Despite this, many studies have found overlap in FFM and TCI dimensions and have demonstrated that these models share many characteristics (De Fruyt et al., 2000; Maggini et al., 2000; Svrakic et al., 1993). Because no study has compared and contrasted the TCI-125 with the PID-5 to date, we sought to clarify the relations between these two instruments and the models on which they are based and examined whether the TCI-125 or the PID-5 dimensions would represent PD-scale scores more effectively and accurately. Additionally, the simultaneous use of these two models' instruments will provide more information about personality and also reduce the weaknesses of any single instrument (Stepp et al., 2012). Therefore, the present study evaluates the hypothesis that the TCI-125 dimensions add meaningful variance beyond the PID-5 in predicting personality disorders.

\section{PARTICIPANTS AND PROCEDURE}

\section{PARTICIPANTS}

The participants were selected from 980 college students who were referred to the psychological servic- 
es center at the University of Kurdistan. 654 students volunteered and agreed to participate in the study. Inclusion criteria were no history of neurological illness, no drug use and/or abuse, and no other serious medical condition. Of the initial volunteer sample, 569 cases were selected. Invalid protocols (e.g., similar responses to all items, not responding to one of the measures) were eliminated. In the final sample $(N=437)$, age ranged from 18 to 56 years $(M=27.17$, $S D=7.18)$, and $56 \%(n=287)$ of them were female. All participants volunteered and agreed to respond to the measures and gave their informed consent to participate. The Research Ethics Committee of the University of Kurdistan (IR.UOK.REC.1397.003) approved this study.

\section{MEASURES}

Personality Inventory for DSM-5 - Persian version. The PID-5 (Krueger et al., 2012) is a self-report inventory consisting of 220 items with a 4-point response scale ranging from 0 (very false or often false) to 3 (very true or often true) that assesses the pathological traits in the DSM-5-III model. It assesses 25 trait facets that load onto five higher-order domains. The five domains (NA - negative affectivity, Det. - detachment, Ant. - antagonism, Dis. - disinhibition, Psy. - psychoticism) were computed based on the average of the three primary facets of any domain: NA (anxiousness, emotional lability, separation insecurity); Det. (anhedonia, intimacy avoidance, withdrawal); Ant. (deceitfulness, grandiosity, manipulativeness); Dis. (distractibility, impulsivity, irresponsibility); Psy. (eccentricity, perceptual dysregulation, unusual beliefs, and experiences) (see Krueger et al., 2013).

To develop the Persian translation of the PID-5, it was first independently translated into Persian by a four-member team that included two English language specialists, a psychologist, and a psychometrics specialist (the first author). For back-translation to English, the final Persian version was given to a professional translator who was uninformed about the original version. The back-translated version was sent for review to the author of the original PID-5 (Krueger), who identified ten items that were significantly different from those in the original version. The translators then modified these items under the supervision of the author of the PID-5 (Krueger). In this study, Cronbach's $\alpha$ for the five domains were .88 (negative affectivity), .89 (detachment), .87 (antagonism), .90 (disinhibition) and .94 (psychoticism). The descriptive details along with IICs (average of interitem correlations) for all five domains and 25 facets are included in Supplementary Table 1.

Temperament and Character Inventory - Persian version. The TCI-125 (Cloninger, 1994) is a 125-item self-report measure of four temperaments (novelty seeking, harm avoidance, reward dependence, and persistence) and three character types (self-directedness, cooperativeness, and self-transcendence). Each item is rated as yes or no. This inventory had been previously translated into Persian and then backtranslated (Kaviani, 2009; Naseh \& Kaviani, 2005). In the current study, Cronbach's $\alpha$ for the seven dimensions were .75 (harm avoidance), .58 (novelty seeking), .47 (reward dependence), .56 (persistence), .83 (self-directedness), .73 (cooperativeness) and .73 (self-transcendence). The descriptive details along with IICs (average of inter-item correlations) for all seven dimensions are reported in Supplementary Table 2.

Structured Clinical Interview for DSM-IV-TR Axis II Screening Questionnaire - Persian version. The SCID-II-SQ (First et al., 1997) is a 119-item questionnaire based on the SCID-II interview, intended to assess the presence of PD symptoms. Each item addresses a specific PD criterion and all items are rated as yes or no. Each PD diagnosis is measured on a scale based on the number of PD criteria endorsed. The usefulness of this instrument in the assessment of DSM PD symptoms has been established (Anderson et al., 2014). In Iran, both the SCID-II and SCID-II-SQ have been translated into Persian and adapted (Amini et al., 2015; Mohammadkhani et al., 2011). In the current study, Cronbach's $\alpha$ for the ten PD scales were .68 (paranoid PD), .72 (schizotypal PD), .47 (schizoid PD), .60 (histrionic PD), .74 (narcissistic PD), .81 (borderline PD), .86 (antisocial PD), .61 (avoidant PD), .64 (dependent PD) and .50 (obsessive-compulsive PD). The descriptive details along with IICs (average of inter-item correlations) for all 10 personality disorders are included in Supplementary Table 3.

\section{STATISTICAL ANALYSES}

For extracting item-related coefficients, the cases with missing data were excluded. The zero-order bivariate correlations of personality traits, temperaments, and characters with the ten PD-scale scores were calculated for the 437 valid cases (see Table 1 and Supplementary Table 4). Then, hierarchical multiple regression analyses were used to predict SCID-II-PD-scale scores by PID-5 domains at the first step and TCI-125 dimensions secondly. Finally, after ensuring that there was no collinearity between the five domains of PID-5 and the seven dimensions of TCI-125, forward multiple regression analyses were used to determine the main predictors of PD-scale scores among 12 variables (PID-5 domains and TCI-125 dimensions, simultaneously). All statistical analyses were conducted through the IBM SPSS-24 software. 


\section{RESULTS}

\section{INCREMENTAL EFFECTS OF TCI-125 COMPONENTS BEYOND THE PID-5 DOMAINS}

Results from the hierarchical multiple regression analyses are presented in Table 2. In these analyses, the PID- 5 domains were added in the first step, then TCI-125 components as a second step to predict the ten SCID-II PD scales. Although the results of bivariate correlations showed that most of the PID- 5 domains were significantly $(p<.001)$ associated with all the PDs (see Supplementary Table 4), the regression analyses, in the first step, yielded more specific results. The PID-5 domains explained a significant portion of the variance for all PDs (range: 16 to .42; $p<.001$ ), with the highest adjusted $R^{2}$ values for borderline (.42), narcissistic (.39), and dependent PDs (.37). As Table 2 shows, paranoid PD had strong relations with negative affectivity $(\beta=.20)$, antagonism $(\beta=.25)$, disinhibition $(\beta=-.23)$, and psychoticism $(\beta=.29)$. Schizotypal PD was associated only with psychoticism $(\beta=.45)$. Schizoid PD was predicted only by detachment $(\beta=.30)$. Histrionic PD was mainly associated with negative affectivity $(\beta=.20)$, detachment $(\beta=-.46)$, antagonism $(\beta=.30)$, and psychoticism $(\beta=.24)$. Narcissistic PD was significantly predicted by negative affectivity $(\beta=.23)$, antago- nism $(\beta=.46)$, and disinhibition $(\beta=-.20)$. Borderline PD was related to psychoticism $(\beta=.23)$ and negative affectivity $(\beta=.22)$. Antisocial PD was significantly predicted only by antagonism $(\beta=.30)$. Avoidant PD was mainly linked with negative affectivity $(\beta=.38)$ and detachment $(\beta=.33)$. Dependent PD was predicted only by negative affectivity $(\beta=.52)$. Finally, obsessive-compulsive PD was associated with negative affectivity $(\beta=.33)$, disinhibition $(\beta=-.27)$, and psychoticism $(\beta=.24)$.

In the second step of hierarchical multiple regression analyses, TCI-125 temperaments and characters were included as predictors of the PDs (see Table 2). Overall, these analyses indicated that TCI-125 dimensions explained a significant portion of the variance for all PDs (adjusted $R^{2}$ values ranged from .16 to .50; $p<.001$ ), and step 2 added between 3\% and 13\% explained variance (i.e., $\Delta R_{\text {adj }}^{2}$ ) beyond step 1 . As Table 2 shows, the temperaments (which predicted only four PDs significantly) added relatively little variance beyond PID-5 domains, whereas the characters (especially self-directedness and cooperativeness) proved to be stronger predictors of PDs. As details of Table 2 indicate, only four PDs were significantly predicted by harm avoidance (avoidant $\mathrm{PD} ; \beta=.39$ ), novelty seeking (borderline $\mathrm{PD} ; \beta=.26$ ), reward dependence (histrionic $\mathrm{PD} ; \beta=.26$ ), and persistence (obsessivecompulsive PD; $\beta=.23$ ). However, self-directedness

Table 1

Bivariate correlations between PID-5 domains and TCI-125 dimensions $(N=437)$

\begin{tabular}{|c|c|c|c|c|c|c|c|c|c|c|c|c|}
\hline \multirow[t]{2}{*}{ Scales } & \multicolumn{12}{|c|}{ Bivariate correlations } \\
\hline & $\mathrm{NA}$ & Det. & Ant. & Dis. & Psy. & $\mathrm{HA}$ & NS & $\mathrm{RD}$ & Per. & SD & Coo. & ST \\
\hline Det. & .46 & & & & & & & & & & & \\
\hline Ant. & .57 & .45 & & & & & & & & & & \\
\hline Dis. & .71 & .61 & .62 & & & & & & & & & \\
\hline Psy. & .65 & .59 & .70 & .68 & & & & & & & & \\
\hline $\mathrm{HA}$ & .44 & .43 & .18 & .38 & .19 & & & & & & & \\
\hline NS & .35 & .12 & .34 & .47 & .30 & .11 & & & & & & \\
\hline $\mathrm{RD}$ & .09 & -.29 & -.10 & -.05 & -.16 & .01 & .10 & & & & & \\
\hline Per. & .06 & .03 & .09 & -.15 & .12 & -.11 & -.17 & -.06 & & & & \\
\hline SD & -.60 & -.48 & -.45 & -.64 & -.47 & -.48 & -.42 & -.03 & .07 & & & \\
\hline Coo. & -.34 & -.33 & -.57 & -.39 & -.44 & -.26 & -.30 & .29 & .03 & .32 & & \\
\hline ST & .20 & .02 & .13 & .06 & .32 & -.18 & -.01 & .05 & .26 & -.15 & .11 & \\
\hline SCID-II Total & .62 & .46 & .63 & .54 & .66 & .30 & .39 & -.10 & .13 & -.61 & -.54 & .30 \\
\hline
\end{tabular}

Note. NA - negative affectivity; Det. - detachment; Ant. - antagonism; Dis. - disinhibition; Psy. - psychoticism; HA - harm avoidance; NS - novelty seeking; RD - reward dependence; Per. - persistence; SD - self-directedness; Coo. - cooperativeness; ST - self-transcendence. All absolute values $>.17$ are significant at $p<.001$. All absolute values $>.12$ are significant at $p<.01$. All absolute values $>.09$ are significant at $p<.05$. 


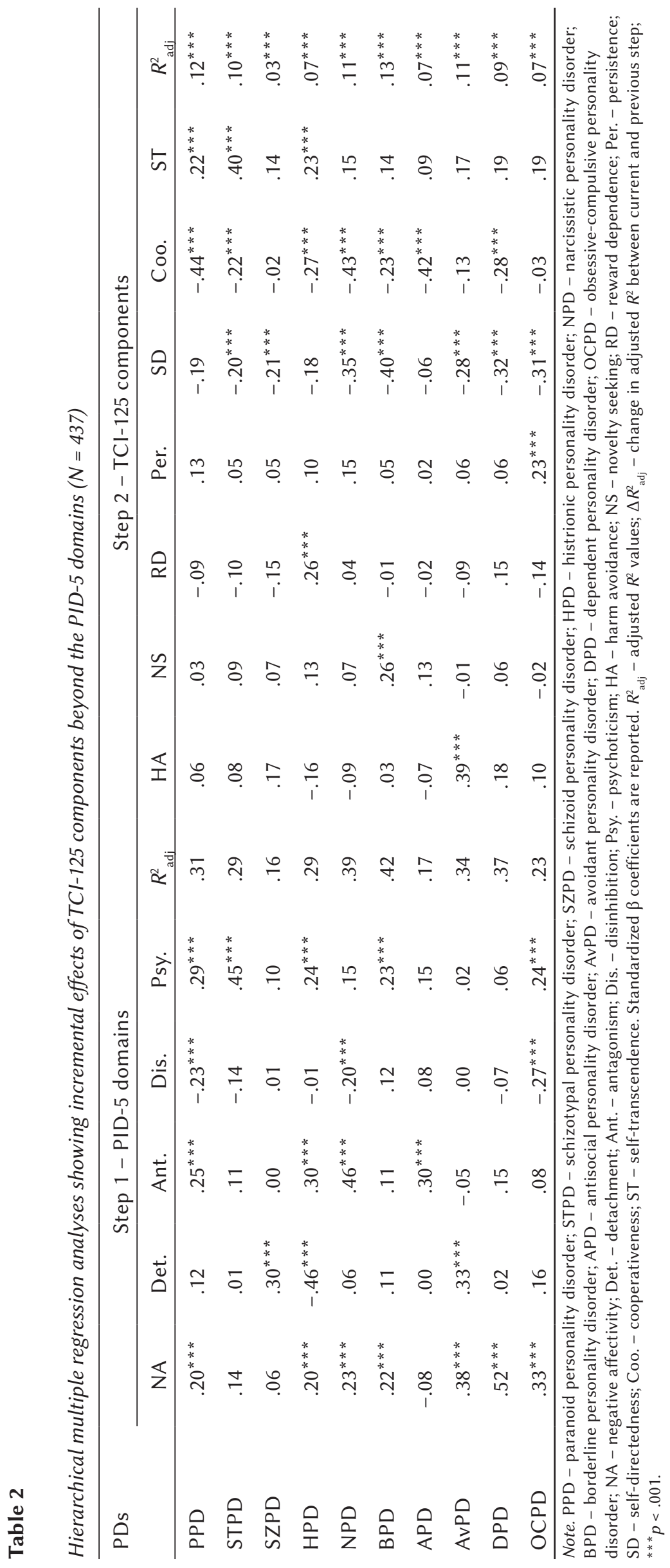


significantly predicted schizotypal $(\beta=-.20)$, schizoid $(\beta=-.21)$, narcissistic $(\beta=-.35)$, borderline $(\beta=-.40)$, avoidant $(\beta=-.28)$, dependent $(\beta=-.32)$ and obsessive-compulsive ( $\beta=-.31$ ) PDs; cooperativeness was a significant predictor of paranoid $(\beta=-.44)$, schizotypal $(\beta=-.22)$, histrionic $(\beta=-.27)$, narcissistic $(\beta=-.43)$, borderline $(\beta=-.23)$, antisocial $(\beta=-.42)$ and dependent $(\beta=-.28)$ PDs; and self-transcendence significantly predicted paranoid $(\beta=.22)$, schizotypal $(\beta=.40)$ and histrionic $(\beta=.23)$ PDs.

\section{FORWARD MULTIPLE REGRESSION MODELS WITH PID-5 AND TCI-125 DIMENSIONS AS PREDICTORS OF PD-SCALE SCORES}

Table 3 shows the results of forward regression models including the PID-5 and TCI-125 dimensions as predictors of each SCID-II PD scale, as well as the SCID-II total, representing overall pathology. All models were significant and notably included at least one PID-5 domain and one TCI-125 dimension as significant predictors. For five out of the ten models plus model 11, a TCI-125 dimension was the strongest predictor of PD. Overall, the results indicated that the most consistent predictors of PD were low self-directedness, high self-transcendence, high psychoticism, and low cooperativeness. The major predictors of paranoid PD were psychoticism, low cooperativeness, self-transcendence, self-directedness, and persistence $(\beta=.12-.41)$. The schizotypal PD was mainly predicted by psychoticism, self-transcendence, low selfdirectedness, and low cooperativeness $(\beta=.17-.30)$. The schizoid PD was significantly linked to detachment, low self-directedness, and self-transcendence $(\beta=.12-.30)$. The main predictors of histrionic PD were antagonism, low detachment, self-transcendence, and low self-directedness $(\beta=.20-.43)$. The narcissism PD was significantly predicted by antagonism, self-directedness, low cooperativeness, and self-transcendence $(\beta=.17-.32)$. The major predictors of borderline PD were psychoticism, detachment, low self-directedness, novelty seeking, low cooperativeness, and detachment $(\beta=.09-.31)$. The main predictors of antisocial PD were psychoticism, low cooperativeness, and novelty seeking ( $\beta=.11-.34$ ). The avoidant PD was associated with psychoticism, detachment, low self-directedness, harm avoidance, and self-transcendence $(\beta=.13-.36)$. The main predictors of dependent PD were negative affectivity, low self-directedness, low cooperativeness, self-transcendence, and reward dependence $(\beta=.12-.34)$. The obsessive-compulsive PD was significantly predicted by psychoticism, persistence, and self-directedness $(\beta=.25-.27)$. For overall personality pathology, as measured by the total score of SCID-II, the main predictors were psychoticism, low self-directedness, low cooperativeness, and self-transcendence $(\beta=.19-.34)$.

\section{DISCUSSION}

This study explored the ability of each of the TCI-125 and the PID-5 to predict PD-scale scores and sought to determine whether the former adds meaningful variance beyond the latter in predicting personality disorders. The results showed that PD-scale scores were uniformly related to the domains of the PID-5, except for the correlation between histrionic PD and detachment. Furthermore, borderline PD was most strongly correlated with all domains, which is consistent with previous research (e.g., Hopwood et al., 2012). However, regression analyses showed that these domains predict the PD-scale scores differentially. In other words, the PID-5 domains are all related to general personality pathology, but examining specific patterns among the domains is necessary to accurately classify PD. This supports research by Skodol et al. (2011) showing that pathological traits facilitate more accurate diagnoses.

With regards to the TCI-125 dimensions, the temperaments and characters generally showed patterns of correlations that were common across most PD-scale scores. Specifically, PD-scale scores were correlated with low reward dependence except for histrionic PD, were associated with high harm avoidance except for histrionic and antisocial PDs, and were associated with high novelty seeking except for obsessive-compulsive PD. The persistence temperament had weak or insignificant correlations with all the PD-scale scores, whereas its association with obsessive-compulsive PD was considerable. All PD-scale scores were correlated with low self-directedness and low cooperativeness characters; in contrast, all of them were associated with high self-transcendence. In summary, the TCI-125 dimensions appear to be associated with personality pathology in general. These results suggest that TCI-125 can recognize the presence of PD but is less useful in classifying the specific PDs, although the temperaments differentiate a small number of PDs.

These findings corroborate the studies reporting that low self-directedness and cooperativeness can be a predictor of the number of personality disorder symptoms (Dereboy et al., 2013; Svrakic et al., 1993, 2002). Also, the temperament scores were more useful in distinguishing between the different types of personality disorder, which is in contrast with other studies that have not corroborated these results (Ball et al., 1997; Gutiérrez et al., 2002; Maggini et al., 2000). Nonetheless, according to Cloninger (2000), all PDs are characterized by low scores in self-directedness, most are also characterized by low cooperativeness, and the more severe personality disorders (e.g., borderline PD) are characterized by low self-transcendence. Cloninger proposes a twostage process in which general criteria for person- 


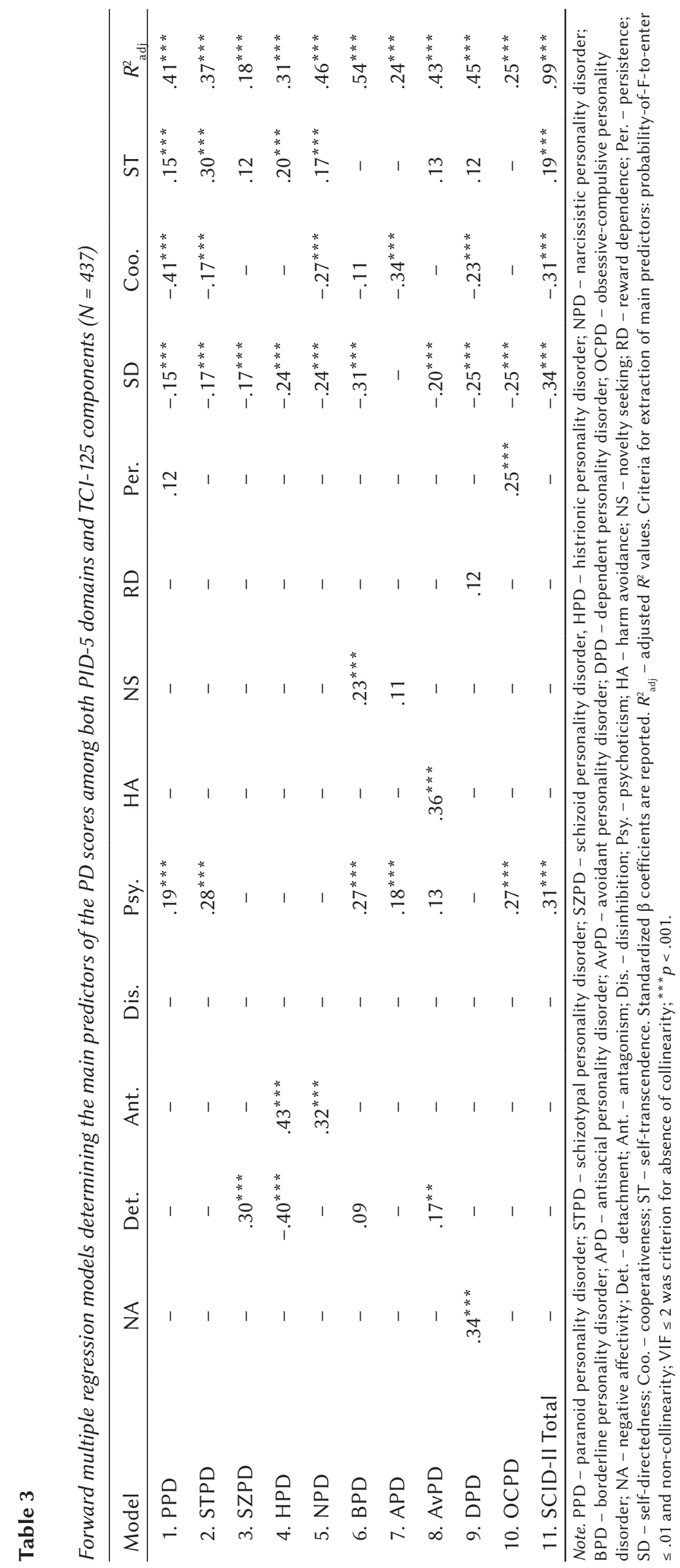


ality disorder are evaluated (low self-directedness, low cooperativeness, low affective stability, and low self-transcendence). If at least two of the general criteria are deemed present, then the patient is subsequently rated on the dimensions of novelty seeking, harm avoidance, and reward dependence in order to subtype the personality pathology. For example, borderline personality disorder is characterized by high novelty seeking, high harm avoidance, and low reward dependence.

The myriad significant correlations between the domains of PID- 5 and the dimensions of TCI- 125 suggested some convergence between these two instruments. However, negative affectivity was not associated with reward dependence or persistence, detachment was not associated with persistence or self-transcendence, antagonism was not associated with persistence, and disinhibition was not associated with reward dependence or self-transcendence. Svrakic et al. (1993) also found that the NEO inventory explained about $40 \%$ of the variance in the TCI and correlated with five of the seven TCI factors, largely failing to explain persistence and self-transcendence.

Stepp et al. (2012) showed that simultaneous use of multiple instruments will provide greater information about personality. Even though the regression models showed approximately equal adjusted $R^{2}$ for PID-5 domains (range: 15 to $.41 ; p<.001$ ) and TCI-125 dimensions (range: .16 to $.50 ; p<.001$ ), the TCI-125 dimensions added between 3 and 13\% explained variance beyond the PID- 5 domains. These results can be compared to the findings of Svrakic et al. (1993), which showed that the TCI predicts the symptoms of PD statistically better than the NEO-PI and suggested that self-directedness better describes the core of PD than FFM dimensions. In contrast, Ball et al. (1997) reported that the NEO-FFI had more predictive power than the TCI for PDsSvrakic et al. (1993). Moreover, this finding is consistent with claims by Trull and Durrett (2005) and Clark (2007), who discussed how dimensional approaches might be integrated into the diagnostic system and assessment model. Widiger et al. (2009) provided one specific possibility, demonstrating how abnormal personality scales from the DAPP-BQ (Livesley \& Jackson, 2009) and SNAP (Clark, 1993) can be integrated with the normal personality scales of the NEO PI-R.

Taken together, significant correlations of pathological trait domains and dimensions with all the 10 PD-scale scores and the total score of SCID-II-Q supported the conclusion of Morey (2017) that the severity rating of pathological traits requires a single rating. Instead of using only the specific diagnostic criteria, diagnoses must account for the severity (Tyrer, 2005) and the overarching defining features of the disorders (Skodol et al., 2011). Such a description is consistent with evidence that the personality features of individuals often differ in degree, not in kind (Markon et al., 2005).

\section{LIMITATIONS}

There are some notable limitations of this study. One is the low $\alpha$ value of some subscales of measures, inevitably affecting the validity of the results. For instance, the results showed that both the PID- 5 and the TCI-125 had the highest adjusted $R^{2}$ in prediction of borderline PD and the lowest adjusted $R^{2}$ for schizoid PD. Probably, these results are due to $\alpha<.50$ for schizoid PD and $\alpha>.80$ for BPD. Additional studies are warranted in order to shed light on this issue. Furthermore, our data are entirely self-reported, which causes greater potential for validity problems than a study that incorporates multiple methods of data collection. Additionally, the Persian translation of the measures were administered in a college student sample in the current study, which may not be fully representative of the Iranian population broadly or clinical populations with substantial personality pathology. Future studies should be carried out on larger clinical samples from a broader range of settings, with a particular emphasis on clinical populations to provide a wider range of traits and more representation at the extreme ends of these traits. Also, only the TCI-125 (Cloninger, 1994) version has been translated and validated in an Iranian sample. In future research, it would be useful to study other revised forms of the TCI, including TCI-140 and TCI-R (Farmer \& Goldberg, 2008), to compare findings.

\section{CONCLUSIONS}

Our study showed that the PID-5 dimensions and the TCI-125 dimensions were generally related to personality pathology. Additionally, combining the PID-5 and TCI-125 dimensions resulted in the greatest adjusted $R^{2}$ values for all PD-scale scores, suggesting that integrating these two instruments will be more useful for accurate diagnosis than either instrument alone. Specifically, the results of forward regression analyses showed that cooperativeness (low), self-directedness (low) and self-transcendence (high) characters of the TCI- 125 and the psychoticism (high) domain of the PID- 5 are the most consistent predictors of all PD-scale scores, and the four temperaments and the other four domains of PID-5 are differential predictors of PD.

\section{ACKNOWLEDGMENTS}

We extend our appreciation to the participants of our study and the students of psychology who helped us in data collection. 


\section{References}

American Psychiatric Association (2013). Diagnostic and statistical manual of mental disorders: DSM-5. APA.

Amini, M., Pourshahbaz, A., Mohammadkhani, P., Ardakani, M. R. K., Lotfi, M., \& Ramezani, M. A. (2015). The relationship between five-factor model and diagnostic and statistical manual of mental disorder-personality traits on patients with antisocial personality disorder. Journal of Research in Medical Sciences: The Official Journal of Isfahan University of Medical Sciences, 20, 470-476. https:// doi.org/10.4103/1735-1995.163970

Anderson, J., Snider, S., Sellbom, M., Krueger, R., \& Hopwood, C. (2014). A comparison of the DSM-5 Section II and Section III personality disorder structures. Psychiatry Research, 216, 363-372. https://doi.org/10.1016/j.psychres.2014.01.007

Ball, S. A., Tennen, H., Poling, J. C., Kranzler, H. R., \& Rounsaville, B. J. (1997). Personality, temperament, and character dimensions and the DSM-IV personality disorders in substance abusers. Journal of Abnormal Psychology, 106, 545-553. https:// doi.org/10.1037/0021-843X.106.4.545

Clark, L. A. (1993). Manual for the schedule for nonadaptive and adaptive personality. University of Minnesota Press.

Clark, L. A. (2005). Temperament as a unifying basis for personality and psychopathology. Journal of Abnormal Psychology, 114, 505-521. https://doi. org/10.1037/0021-843X.114.4.505

Clark, L. A. (2007). Assessment and diagnosis of personality disorder: Perennial issues and an emerging reconceptualization. Annual Review of Psychology, 58, 227-257. https://doi.org/10.1146/annurev. psych.57.102904.190200

Clark, L. A., Simms, L. J., Wu, K. D., \& Casillas, A. (2014). Manual for the schedule for nonadaptive and adaptive personality (SNAP-2). University of Notre Dame.

Clark, L. A., Vanderbleek, E. N., Shapiro, J. L., Nuzum, H., Allen, X., Daly, E., Kingsbury, T. J., Oiler, M., \& Ro, E. (2015). The brave new world of personality disordertrait specified: Effects of additional definitions on coverage, prevalence, and comorbidity. Psychopathology Review, 2, 52-82. https://doi.org/10.5127/pr.036314

Cloninger, C. R. (1994). The temperament and character inventory (TCI): a guide to its development and use. Center for Psychobiology of Personality, Washington University.

Cloninger, C. R. (2000). A practical way to diagnosis personality disorder: a proposal. Journal of Personality Disorders, 14, 99-108. https://doi.org/10.1521/ pedi.2000.14.2.99

Cloninger, C. R., Svrakic, D. M., \& Przybeck, T. R. (1993). A psychobiological model of temperament and character. Archives of General Psychiatry, 50, 975-990. https://doi.org/10.1001/archpsyc. 1993.01820240059008
De Caluwé, E., Verbeke, L., Aken, M. V., Heijden, P. T. V. D., \& Clercq, B. D. (2019). The DSM-5 trait measure in a psychiatric sample of late adolescents and emerging adults: Structure, reliability, and validity. Journal of Personality Disorders, 33, 101-118. https://doi.org/10.1521/pedi_2018_32_333

De Fruyt, F., Van De Wiele, L., \& Van Heeringen, C. (2000). Cloninger's psychobiological model of temperament and character and the five-factor model of personality. Personality and Individual Differences, 29, 441-452. https://doi.org/10.1016/ S0191-8869(99)00204-4

de la Rie, S. M., Duijsens, I. J., \& Cloninger, C. R. (1998). Temperament, character, and personality disorders. Journal of Personality Disorders, 12, 362372. https://doi.org/10.1521/pedi.1998.12.4.362

Dereboy, C., Güzel, H. S., Dereboy, F., Okyay, P., \& Eskin, M. (2013). Personality disorders in a community sample in Turkey: Prevalence, associated risk factors, temperament and character dimensions. International Journal of Social Psychiatry, 60, 139147. https://doi.org/10.1177/0020764012471596

Farmer, R. F., \& Goldberg, L. R. (2008). A psychometric evaluation of the revised Temperament and Character Inventory (TCl-R) and the TCl-140. Psychological Assessment, 20, 281-291. https://doi. org/10.1037/a0012934

First, M. B., Gibbon, M., Spitzer, R. L., Williams, J. B. W., \& Benjamin, L. S. (1997). User's guide for the Structured Clinical Interview for DSM-IV Axis II personality disorders: SCID-II. American Psychiatric Press.

García, L. F., Cuevas, L., Lucas, I., \& Aluja, A. (2020). Comparing the prediction of dimensional personality disorders (PID-5) after three personality trait models: Five factor, Zuckerman, and Cloninger models. European Journal of Psychological Assessment. https://doi.org/10.1027/1015-5759/a000601

Gutiérrez, F., Sangorrín, J., Martín-Santos, R., Torres, X., \& Torrens, M. (2002). Measuring the core features of personality disorders in substance abusers using the Temperament and Character Inventory ( $\mathrm{TCl}$ ). Journal of Personality Disorders, 16, 344-359. https:// doi.org/10.1521/pedi.16.4.344.24125

Hopwood, C. J., Thomas, K. M., Markon, K. E., Wright, A. G. C., \& Krueger, R. F. (2012). DSM-5 personality traits and DSM-IV personality disorders. Journal of Abnormal Psychology, 121, 424432. https://doi.org/10.1037/a0026656

Jopp, A. M., \& South, S. C. (2014). Investigating the personality inventory for DSM-5 using self and spouse reports. Journal of Personality Disorders, 29, 193-214. https://doi.org/10.1521/pedi_2014_28_153

Kaviani, H. (2009). Normative data on Temperament and Character Inventory (TCl): Complimentary findings. Tehran University Medical Journal, 67, 262-266.

Kendler, K. S. (2009). An historical framework for psychiatric nosology. Psychological Medicine, 39, 19351941. https://doi.org/10.1017/S0033291709005753 
Krueger, R. F., Derringer, J., Markon, K. E., Watson, D., \& Skodol, A. (2012). Initial construction of a maladaptive personality trait model and inventory for DSM-5. Psychological Medicine, 42, 1879-1890. https://doi.org/10.1017/S003329171100267

Krueger, R. F., Derringer, J., Markon, K. E., Watson, D., \& Skodol, A. E. (2013). The personality inventory for DSM-5 (PID-5). APA.

Krueger, R. F., \& Markon, K. E. (2006). Reinterpreting comorbidity: a model-based approach to understanding and classifying psychopathology. Annual Review of Clinical Psychology, 2, 111-133. https:// doi.org/10.1146/annurev.clinpsy.2.022305.095213

Livesley, W. J., \& Jackson, D. (2009). Manual for the dimensional assessment of personality pathology basic questionnaire. Sigma.

Maggini, C., Ampollini, P., Marchesi, C., Gariboldi, S., \& Cloninger, C. R. (2000). Relationships between Tridimensional Personality Questionnaire dimensions and DSM-III-R personality traits in Italian adolescents. Comprehensive Psychiatry, 4, 426-431. https://doi.org/10.1053/comp.2000.16559

Markon, K. E., Krueger, R. F., \& Watson, D. (2005). Delineating the structure of normal and abnormal personality: an integrative hierarchical approach. Journal of Personality and Social Psychology, 88, 139157. https://doi.org/10.1037/0022-3514.88.1.139

Miller, J. D., McCain, J., Lynam, D. R., Few, L. R., Gentile, B., MacKillop, J., \& Campbell, W. K. (2014). A comparison of the criterion validity of popular measures of narcissism and narcissistic personality disorder via the use of expert ratings. Psychological Assessment, 26, 958-969. https://doi. org/10.1037/a0036613

Miller, J. D., Reynolds, S. K., \& Pilkonis, P. A. (2004). The validity of the five-factor model prototypes for personality disorders in two clinical samples. Psychological Assessment, 16, 310-322. https://doi. org/10.1037/1040-3590.16.3.310

Mohammadkhani, P., Jokar, M., Jahani-Tabesh, O., \& Tamannaei-Far, S. (2011). Structured Clinical Interview for DSM-IV Axis II personality disorders (Persian version). Danjeh.

Morey, L. C. (2017). Application of the DSM-5 level of Personality Functioning Scale by Lay Raters. Journal of Personality Disorders, 32, 709-720. https:// doi.org/10.1521/pedi_2017_31_305

Naseh, M. P., \& Kaviani, H. (2005). Validation of Temperament and Character Inventory $(\mathrm{TCl})$ in Iranian sample: normative data. Tehran University Medical Journal, 63, 89-98.

Sadock, B. J., Sadock, V. A., \& Ruiz, P. (2017). Kaplan and Sadock's comprehensive textbook of psychiatry. Wolters Kluwer Health.

Samuel, D. B., \& Widiger, T. A. (2008). A meta-analytic review of the relationships between the five-factor model and DSM-IV-TR personality disorders: a facet level analysis. Clinical Psychology $R e-$ view, 28, 1326-1342. https://doi.org/10.1016/j.cpr. 2008.07.002

Saulsman, L. M., \& Page, A. C. (2004). The five-factor model and personality disorder empirical literature: a meta-analytic review. Clinical Psychology Review, 23, 1055-1085. https://doi.org/10.1016/j.cpr. 2002.09.001

Skodol, A. E., Bender, D. S., Oldham, J. M., Clark, L. A., Morey, L. C., Verheul, R., Krueger, R. F., \& Siever, L. J. (2011). Proposed changes in personality and personality disorder assessment and diagnosis for DSM-5 Part II: Clinical application. Personality Disorders, 2, 23-40. https://doi.org/10.1037/a0021892

Stepp, S. D., Yu, L., Miller, J. D., Hallquist, M. N., Trull, T. J., \& Pilkonis, P. A. (2012). Integrating competing dimensional models of personality: Linking the SNAP, TCl, and NEO using item response theory. Personality Disorders, 3, 107-126. https://doi.org/10.1037/a0025905

Svrakic, M. D., Draganic, S., Hill, K., Bayon, C., Przybeck, T. R., \& Cloninger, C. R. (2002). Temperament, character, and personality disorders: Etiologic, diagnostic, treatment issues. Acta Psychiatrica Scandinavica, 106, 189-195. https://doi. org/10.1034/j.1600-0447.2002.02196.x

Svrakic, M. D., Whitehead, C., Przybeck, R. T., \& Cloninger, C. R. (1993). Differential diagnosis of personality disorders by the seven-factor model of temperament and character. Archives of General Psychiatry, 50, 991-999. https://doi.org/10.1001/ archpsyc. 1993.01820240075009

Trull, T. J., \& Durrett, C. A. (2005). Categorical and dimensional models of personality disorder. Annual Review of Clinical Psychology, 1, 355-380. https:// doi.org/10.1146/annurev.clinpsy.1.102803.144009

Tyrer, P. (2005). The problem of severity in the classification of personality disorder. Journal of Personality Disorders, 19, 309-314. https://doi.org/10.1521/ pedi.2005.19.3.309

Watson, D., Stasik, S. M., Ro, E., \& Clark, L. A. (2013). Integrating normal and pathological personality: Relating the DSM-5 trait-dimensional model to general traits of personality. Assessment, 20, 312326. https://doi.org/10.1177/1073191113485810

Widiger, T. A., Costa, P. T., Jr., \& McCrae, R. R. (2002). A proposal for Axis II: Diagnosing personality disorders using the five-factor model. In P. T. Costa, Jr. \& T. A. Widiger (Eds.), Personality disorders and the five-factor model of personality (pp. 431456). American Psychological Association.

Widiger, T. A., Livesley, W. J., \& Clark, L. A. (2009). An integrative dimensional classification of personality disorder. Psychological Assessment, 21, 243-255. https://doi.org/10.1037/a0016606

Widiger, T. A., \& Simonsen, E. (2005). Alternative dimensional models of personality disorder: Finding a common ground. Journal of Personality Disorders, 19, 110-130. https://doi.org/10.1521/pedi.19.2.110.62628 


\section{Supplementary Table 1}

Descriptive statistics and internal consistency for PID-5 domains/facets $(N=437)$

\begin{tabular}{|c|c|c|c|c|}
\hline Scales & M & $S D$ & $\alpha$ & IIC \\
\hline \multicolumn{5}{|l|}{ PID-5 domains } \\
\hline Negative affectivity & 8.90 & 3.33 & .88 & .24 \\
\hline Detachment & 7.85 & 3.24 & .89 & .26 \\
\hline Antagonism & 6.57 & 2.78 & .87 & .24 \\
\hline Disinhibition & 6.88 & 3.20 & .90 & .29 \\
\hline Psychoticism & 10.03 & 5.20 & .94 & .34 \\
\hline \multicolumn{5}{|l|}{ PID-5 facets } \\
\hline Anxiousness & 11.63 & 5.07 & .85 & .38 \\
\hline Emotion lability & 8.19 & 3.36 & .69 & .25 \\
\hline $\begin{array}{l}\text { Separation } \\
\text { insecurity }\end{array}$ & 6.87 & 3.50 & .71 & .25 \\
\hline Hostility & 12.31 & 5.10 & .82 & .31 \\
\hline Perseveration & 10.46 & 4.08 & .76 & .26 \\
\hline $\begin{array}{l}\text { Restricted affect } \\
\text { (lack of) }\end{array}$ & 7.50 & 3.12 & .66 & .22 \\
\hline Submissiveness & 5.35 & 1.89 & .50 & .20 \\
\hline Anhedonia & 8.09 & 3.74 & .78 & .31 \\
\hline Intimacy avoidance & 6.09 & 2.78 & .63 & .22 \\
\hline Withdrawal & 9.35 & 4.92 & .85 & .36 \\
\hline Suspiciousness & 8.66 & 2.93 & .57 & .16 \\
\hline Depressivity & 12.40 & 7.05 & .89 & .37 \\
\hline Callousness & 9.93 & 5.62 & .83 & .27 \\
\hline Deceitfulness & 8.70 & 4.80 & .81 & .30 \\
\hline Manipulativeness & 3.95 & 2.24 & .53 & .24 \\
\hline Attention seeking & 9.95 & 4.40 & .76 & .34 \\
\hline Grandiosity & 7.06 & 2.86 & .71 & .29 \\
\hline Irresponsibility & 5.56 & 3.29 & .75 & .31 \\
\hline Impulsivity & 5.37 & 3.41 & .82 & .44 \\
\hline Risk taking & 20.16 & 5.41 & .77 & .20 \\
\hline $\begin{array}{l}\text { Rigid perfectionism } \\
\text { (lack of) }\end{array}$ & 14.54 & 4.71 & .78 & .26 \\
\hline Distractibility & 9.72 & 4.75 & .85 & .39 \\
\hline Eccentricity & 11.91 & 7.25 & .92 & .47 \\
\hline $\begin{array}{l}\text { Perceptual } \\
\text { dysregulation }\end{array}$ & 10.60 & 5.82 & .85 & .32 \\
\hline Unusual beliefs & 7.58 & 4.38 & .80 & .34 \\
\hline
\end{tabular}

\section{Supplementary Table 2}

Descriptive statistics and internal consistency for TCl-125 dimensions $(N=437)$

\begin{tabular}{lcccc}
\hline TCl-125 dimensions & $M$ & $S D$ & $\alpha$ & IIC \\
\hline Harm avoidance & 8.43 & 4.14 & .75 & .15 \\
Novelty seeking & 8.53 & 3.10 & .58 & .07 \\
Reward dependence & 8.70 & 2.43 & .47 & .06 \\
Persistence & 2.76 & 1.49 & .56 & .20 \\
Self-directedness & 15.28 & 5.22 & .83 & .17 \\
Cooperativeness & 16.96 & 4.00 & .73 & .11 \\
Self-transcendence & 7.22 & 3.12 & .73 & .16 \\
\hline
\end{tabular}

\section{Supplementary Table 3}

Descriptive statistics and internal consistency for SCID-II-Q personality disorders $(N=437)$

\begin{tabular}{lcccc}
\hline SCID-II-Q PDs & $M$ & $S D$ & $\alpha$ & IIC \\
\hline Paranoid PD & 2.44 & 1.99 & .68 & .21 \\
Schizotypal PD & 2.90 & 2.44 & .72 & .19 \\
Schizoid PD & 2.28 & 1.58 & .47 & .13 \\
Histrionic PD & 2.84 & 1.81 & .60 & .18 \\
Narcissistic PD & 5.67 & 3.39 & .74 & .15 \\
Borderline PD & 4.12 & 3.41 & .81 & .22 \\
Antisocial PD & 1.69 & 2.71 & .86 & .29 \\
Avoidant PD & 2.03 & 1.69 & .61 & .18 \\
Dependent PD & 1.96 & 1.82 & .64 & .19 \\
Obsessive-compulsive & 3.91 & 1.91 & .50 & .10 \\
PD & & & & \\
\hline
\end{tabular}




\section{Supplementary Table 4}

Bivariate correlations of all variables with SCID-II-Q personality disorders $(N=437)$

\begin{tabular}{|c|c|c|c|c|c|c|c|c|c|c|}
\hline \multirow[t]{2}{*}{ Scales } & \multicolumn{10}{|c|}{ SCID-II-Q PDs } \\
\hline & PPD & STPD & SZPD & HPD & NPD & BPD & APD & AvPD & DPD & OCPD \\
\hline \multicolumn{11}{|l|}{ PID-5 domains } \\
\hline Negative affectivity & .42 & .40 & .27 & .32 & .47 & .56 & .25 & .52 & .60 & .41 \\
\hline Detachment & .36 & .31 & .38 & .11 & .34 & .46 & .24 & .49 & .32 & .33 \\
\hline Antagonism & .48 & .43 & .24 & .38 & .60 & .51 & .41 & .33 & .45 & .34 \\
\hline Disinhibition & .34 & .34 & .30 & .22 & .38 & .56 & .31 & .45 & .44 & .27 \\
\hline Psychoticism & .51 & .53 & .32 & .32 & .52 & .59 & .36 & .43 & .46 & .42 \\
\hline \multicolumn{11}{|l|}{ PID-5 facets } \\
\hline Anxiousness & .40 & .33 & .29 & .24 & .37 & .49 & .16 & .49 & .49 & .41 \\
\hline Emotional lability & .37 & .39 & .26 & .30 & .45 & .55 & .25 & .42 & .46 & .34 \\
\hline $\begin{array}{l}\text { Separation } \\
\text { insecurity }\end{array}$ & .27 & .30 & .10 & .29 & .38 & .37 & .23 & .35 & .56 & .25 \\
\hline Hostility & .51 & .31 & .24 & .31 & .49 & .52 & .26 & .36 & .36 & .35 \\
\hline Perseveration & .40 & .37 & .28 & .23 & .46 & .49 & .18 & .45 & .48 & .44 \\
\hline $\begin{array}{l}\text { Restricted } \\
\text { affectivity }\end{array}$ & .25 & .22 & .26 & .07 & .28 & .33 & .18 & .32 & .20 & .36 \\
\hline Submissiveness & .13 & .16 & .06 & .15 & .12 & .18 & .08 & .22 & .35 & .19 \\
\hline Anhedonia & .32 & .25 & .37 & .06 & .30 & .46 & .18 & .44 & .34 & .29 \\
\hline Intimacy avoidance & .22 & .19 & .23 & -.13 & .13 & .22 & .16 & .25 & .13 & .20 \\
\hline Withdrawal & .34 & .32 & .36 & .06 & .36 & .45 & .24 & .49 & .29 & .31 \\
\hline Suspiciousness & .53 & .45 & .36 & .25 & .52 & .49 & .27 & .42 & .34 & .44 \\
\hline Depressivity & .34 & .30 & .33 & .11 & .36 & .59 & .24 & .52 & .51 & .30 \\
\hline Callousness & .42 & .30 & .28 & .13 & .45 & .42 & .38 & .27 & .34 & .30 \\
\hline Deceitfulness & .42 & .39 & .23 & .35 & .54 & .49 & .39 & .36 & .44 & .27 \\
\hline Manipulativeness & .40 & .28 & .20 & .28 & .43 & .41 & .37 & .25 & .39 & .25 \\
\hline Attention seeking & .41 & .39 & .15 & .51 & .52 & .42 & .19 & .28 & .40 & .31 \\
\hline Grandiosity & .38 & .37 & .18 & .30 & .50 & .35 & .25 & .17 & .27 & .35 \\
\hline Irresponsibility & .32 & .25 & .27 & .12 & .32 & .43 & .33 & .35 & .34 & .18 \\
\hline Impulsivity & .26 & .24 & .18 & .21 & .30 & .49 & .27 & .29 & .32 & .16 \\
\hline Risk taking & .11 & .13 & .09 & .20 & .20 & .19 & .20 & -.13 & .08 & .10 \\
\hline Rigid perfectionism & .39 & .30 & .20 & .22 & .38 & .28 & .09 & .32 & .33 & .53 \\
\hline Distractibility & .27 & .34 & .28 & .20 & .34 & .48 & .21 & .46 & .42 & .32 \\
\hline Eccentricity & .45 & .44 & .30 & .26 & .46 & .55 & .31 & .38 & .37 & .38 \\
\hline $\begin{array}{l}\text { Perceptual } \\
\text { dysregulation }\end{array}$ & .48 & .48 & .32 & .29 & .49 & .56 & .35 & .45 & .51 & .41 \\
\hline Unusual beliefs/exp & .44 & .53 & .22 & .31 & .45 & .47 & .32 & .30 & .37 & .34 \\
\hline
\end{tabular}




\section{Supplementary Table 4}

(Supplementary Table 4 continued)

\begin{tabular}{|c|c|c|c|c|c|c|c|c|c|c|}
\hline \multirow[t]{2}{*}{ Scales } & \multicolumn{10}{|c|}{ SCID-II-Q PDs } \\
\hline & PPD & STPD & SZPD & HPD & NPD & BPD & APD & $A v P D$ & DPD & OCPD \\
\hline \multicolumn{11}{|l|}{$\mathrm{TCl}$ dimensions } \\
\hline Harm avoidance & .22 & .17 & .25 & .08 & .16 & .28 & .08 & .52 & .37 & .19 \\
\hline Novelty seeking & .21 & .23 & .15 & .27 & .32 & .49 & .27 & .17 & .30 & .10 \\
\hline $\begin{array}{l}\text { Reward } \\
\text { dependence }\end{array}$ & -.21 & -.13 & -.13 & .20 & -.03 & .06 & -.12 & -.11 & -.10 & -.15 \\
\hline Persistence & .16 & .12 & .04 & .11 & .15 & .07 & .09 & .10 & .04 & .26 \\
\hline Self-directedness & -.39 & -.40 & -.34 & -.27 & -.49 & -.62 & -.23 & -.53 & -.55 & -.36 \\
\hline Cooperativeness & -.52 & -.32 & -.17 & -.22 & -.51 & -.43 & -.46 & -.33 & -.38 & -.17 \\
\hline Self-transcendence & .22 & .40 & .15 & .29 & .21 & .18 & .07 & .14 & .21 & .27 \\
\hline
\end{tabular}

